Check for updates

Cite this: RSC Adv., 2019, 9, 37119

\title{
Fluorine ion induced phase evolution of tin-based perovskite thin films: structure and properties $\uparrow$
}

\author{
Junsheng Wu, (D) ab Fang Fang, ${ }^{a}$ Zhuo Zhao, (D) ab Tong Li, ${ }^{\text {ab }}$ Rizwan Ullah, ${ }^{\mathrm{c}}$ Zhe Lv, ${ }^{\mathrm{b}}$ \\ Yanwen Zhou ${ }^{\star a}$ and David Sawtell ${ }^{\star d}$
}

To study the effect of fluorine ions on the phase transformation of a tin-based perovskite, $\mathrm{CsSn}_{3-x}(\mathrm{~F})_{x}$ films were deposited by using thermal vacuum evaporation from a mixed powder of $\mathrm{Snl}_{2}, \mathrm{SnF}_{2}$ and Csl, followed by rapid vacuum annealing. The color evolution, structure, and properties of $\mathrm{CsSnl}_{3-x} \mathrm{~F}_{x}$ films aged in air were observed and analyzed. The results showed that the colors of the films changed from black to yellow, and finally presented as black again over time; the unstable $\mathrm{B}-\gamma-\mathrm{CsSnl}{ }_{3-x} \mathrm{~F}_{x}$ phase transformed into the $\mathrm{Y}-\mathrm{CsSnl}_{3-x} \mathrm{~F}_{x}$ phase, which is then recombined into the $\mathrm{Cs}_{2} \mathrm{Snl}_{6-x} \mathrm{~F}_{x}$ phase with the generation of $\mathrm{SnO}_{2}$ in air. Fluorine dopant inhibited the oxidation process. The postponement of the phase transformation is due to the stronger bonds between $\mathrm{F}$ and $\mathrm{Sn}$ than that between I and Sn. The color changing process of the $\mathrm{CsSnl}_{3-x} \mathrm{~F}_{x}$ films slowed that the hole concentrations increased and the resistivities decreased with the increase of the $\mathrm{F}$ dopant ratio. With the addition of $\mathrm{SnF}_{2}$, light harvesting within the visible light region was significantly enhanced. Comparison of the optical and electrical properties of the fresh annealed $\mathrm{CsSnl}_{3-x} \mathrm{~F}_{x}$ films showed that the band gaps of the aged films widened, the hole concentrations kept the same order, the hole mobilities reduced and therefore, the resistivities increased. The double layer $\mathrm{Cs}_{2} \mathrm{Snl}_{6-x} \mathrm{~F}_{x}$ phase also showed ' $\mathrm{p}$ ' type semi-conductor properties, which might be due to the incomplete transition of $\mathrm{Sn}^{2+}$ to $\mathrm{Sn}^{4+}$, i.e. $\mathrm{Sn}^{2+}$ provides holes as the acceptor.

Received 15th September 2019 Accepted 30th October 2019

DOI: 10.1039/c9ra07415e

rsc.li/rsc-advances the photogenic carriers is limited because of too many p-type carriers produced by the self-doping effect within the tinbased perovskite materials; (2) $\mathrm{SnI}_{2}$ and $\mathrm{MAI}\left(\mathrm{CH}_{3} \mathrm{NH}_{3} \mathrm{I}^{-}\right)$ reacts quickly and rapidly crystallizes during spin-coating process $^{9,11}$ and therefore, it is difficult to control the crystallinity of perovskite, lead to poor coverage and uniformity of the film. To combat this stable and defect free $\mathrm{ASnX}_{3}$ films are required.

Inorganic materials generally have higher stability than organic materials. For this reason, the studies on inorganic perovskite materials have been proposed. As the standard $\mathrm{ASnX}_{3}$ perovskite, the schematic crystal structure of B- $\gamma-\mathrm{CsSnI}_{3}$, Y-CsSnI ${ }_{3}$ and $\mathrm{Cs}_{2} \mathrm{SnI}_{6}$ are shown in Fig. 1 , in which the B- $\gamma$ $\mathrm{CsSnI}_{3}$ phase is black with a three dimensional perovskite structure, ${ }^{12}$ the $\mathrm{Y}^{-\mathrm{CsSnI}_{3}}$ phase is yellow with a one-dimensional double-chain structure, ${ }^{13}$ and $\mathrm{Cs}_{2} \mathrm{SnI}_{6}$ is black with double layer perovskite structure. The unstable B- $\gamma$ - $\mathrm{CsSnI}_{3}$ phase promptly transforms to the $\mathrm{Y}^{-\mathrm{CsSnI}_{3}}$ phase, then forms into the $\mathrm{Cs}_{2} \mathrm{SnI}_{6}$ phase in air, accompanied with the formation of $\mathrm{SnO}_{2}$. The compound of $\mathrm{Cs}_{2} \mathrm{SnI}_{6}$ exhibits its stability in damp air due to the stable $\mathrm{Sn}^{4+}$ state. The 'vacancy ordered' double layer perovskite structure is formed by the missing half of the $\mathrm{Sn}$ atoms located in the center of octahedral, and then reconstitutes to the discontinuous regular octahedral structure $\left(\mathrm{SnI}_{6}\right)^{2-14}$

\footnotetext{
${ }^{a}$ School of Chemical Engineering, University of Science and Technology Liaoning, 114051 Liaoning, Anshan, China

${ }^{b}$ Institute of Surface Engineering, University of Science and Technology Liaoning, Anshan, 114051 Liaoning, China.E-mail: zhouyanwen@ustl.edu.cn

${ }^{c}$ Department of Physics, Beijing Normal University, 100875 Beijing, China

${ }^{d}$ Surface Engineering Group, Manchester Metropolitan University, Manchester M1 5GD, England, UK. E-mail: d.sawtell@mmu.ac.uk

$\dagger$ Electronic supplementary information (ESI) available. See DOI: 10.1039/c9ra07415e
} 


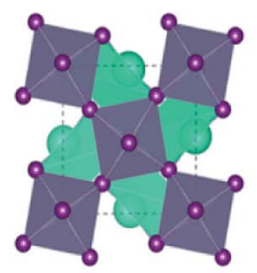

(a) $\mathrm{B}-\gamma-\mathrm{CsSnI}_{3}$

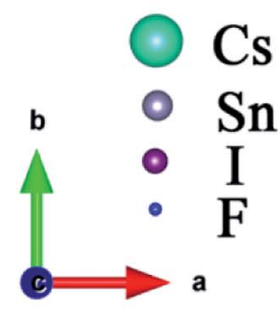

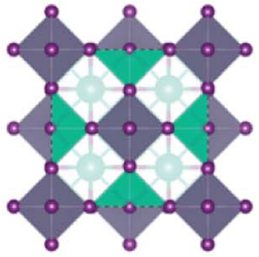

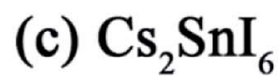

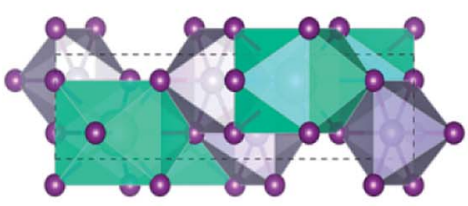

(b) $\mathrm{Y}-\mathrm{CsSnI}$

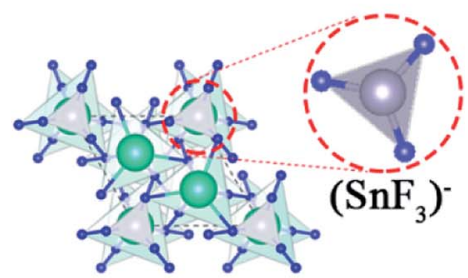

(d) $\mathrm{CsSnF}_{3}$

Fig. 1 Polyhedral model of (a) B- $\gamma-\mathrm{CsSnl}_{3}$. (b) $\mathrm{Y}-\mathrm{CsSnl}_{3}$. (c) $\mathrm{Cs}_{2} \mathrm{Snl}_{6}$ and (d) $\mathrm{CsSnF}_{3}$. Snl ${ }_{6}$ octahedra are in gray, $\mathrm{Cs}$ is in green, $\mathrm{Sn}$ is in gray, the I anions are purple, and $\mathrm{F}$ is blue.

$\mathrm{ASnX}_{3}$ perovskite structure $\left(\mathrm{A}=\right.$ metal or $\mathrm{NH}_{4}$ and $\mathrm{X}=$ halogen family) generally consists of $\left(\mathrm{SnX}_{3}\right)^{-}$and $\mathrm{M}^{+}$, in which $\mathrm{Sn}^{2+}$ is unstable. Vilminot originally discussed evolution of the ionic-conductivity of the $\mathrm{MSnF}_{3}$ phases $\left(\mathrm{M}=\mathrm{Na}, \mathrm{K}, \mathrm{Rb}, \mathrm{Cs}, \mathrm{NH}_{4}\right.$, $\mathrm{Tl}$ ) in $1985 .{ }^{15}$ For example, $\mathrm{CsSnF}_{3}$ exhibits a crystal structure consisting of isolated $\left(\mathrm{SnF}_{3}\right)^{-}$anionic polyhedral, ${ }^{16}$ shown in Fig. 1d. Each $\mathrm{Sn}^{2+}$ cation in $\mathrm{CsSnF}_{3}$ is bonded to three fluorine atoms in a distorted triangular pyramidal coordination environment, i.e. the lone pair of $5 \mathrm{~s}$ electrons of tin(II) and three pairs of electrons, shared unequally with the fluorine ions, occupied on the most stable configuration $\mathrm{sp}^{3}$ hybridization orbits. ${ }^{17}$

Researchers and experiments have shown that the tolerance factors of the stable perovskite materials should be between $0.78-1.05,{ }^{18}$ in which the tolerance factor, $t=\left(R_{\mathrm{A}}+R_{\mathrm{X}}\right) / \sqrt{ } 2\left(R_{\mathrm{B}}+\right.$ $R_{\mathrm{X}}$ ). In the formula, $R_{\mathrm{A}}$ is the radius of monovalent cation, $R_{\mathrm{B}}$, the radius of divalent metal cations and $R_{\mathrm{X}}$, the radius of the halide ion. If there are multiple ions in the $\mathrm{A}$ and/or $\mathrm{B}$ positions, the average radius should be taken. The perovskite structure tends to be stable when $t$ is close to 1 . By calculation, the ' $t$ ' of $\mathrm{CsSnI}_{3-x} \mathrm{~F}_{x}$ is within $0.8734-0.9587$, and $t$ gets larger as the $\mathrm{F}$ ratio increases. That means that the perovskite structure of $\mathrm{CsSnF}_{3}$ is more stable than that of $\mathrm{CsSnI}_{3}$, and $\mathrm{F}$ doped in $\mathrm{CsSnI}_{3}$ may delay the phase transformation of $\mathrm{CsSnI}_{3}$.

The crystal parameters of the $\mathrm{CsSnI}(\mathrm{F})_{3}$ phases are shown in Table 1. The Sn-I bond length is stretched whilst the B- $\gamma-\mathrm{CsSnI}_{3}$ phase transformed into $\mathrm{Y}^{-\mathrm{CsSnI}_{3}}$, and then shortened along with the initial formation of the stable $\mathrm{Cs}_{2} \mathrm{SnI}_{6}$ during the process of tin oxidization. There are many factors affecting bond length and bond energy, such as atomic radius, distance between nuclei, repulsive force between lone pair electrons, feedback bond and so on. In ionic compound, ion radius is the main contributor to bond length. Therefore, the Sn-F bond length in $\mathrm{CsSnF}_{3}$ is less than the bond length of Sn-I in $\mathrm{CsSnI}_{3}$, the difference between them is $1.1321 \AA$ due to the much smaller ionic radii of F (1.33 $\AA$ ) compared to I $(2.20 \AA)$. Generally, the order of stability of the halide complexes of $\operatorname{tin}(\mathrm{II})$ is $\mathrm{F}>$ $\mathrm{Cl}>\mathrm{Br}>\mathrm{I},{ }^{17} \operatorname{tin}(\mathrm{II})$ preferentially bonds with fluoride ion. Hence, $\mathrm{SnF}_{2}$ was introduced as the doping source to improve the stability of tin-based perovskite materials. Meanwhile, as an antioxidant, fluoride ion inhibits the oxidation process of $\mathrm{Sn}^{2+},{ }^{10,19}$ the fluorine also reduces the densities of the materials, which improves their performance when used as a photovoltaic material. ${ }^{20}$

Even though the main method to prepare $\mathrm{CsSnI}_{3}$ films is still the one-step solution based process, it is difficult to produce dense, pinhole free film due to the rapid crystallization of tinbased perovskite., ${ }^{90-22}$ The films prepared by this method are very sensitive to film formation conditions, such as annealing temperature, ${ }^{23,24}$ solution concentration, ${ }^{25,26}$ precursor solution composition $^{27,28}$ and solvent selection..$^{29-31}$ Due to the evaporation of the solvent and the volatilization of the materials during the process of annealing, the crystal tends to easily aggregate and shrink, and the morphology of the films are mainly clusterlike and needle-like, so it is easy to cause the devices' efficiencies to be uneven. The thermal vacuum evaporation technique is an effective approach to prepare high coverage homogeneous thin films and has been widely used in lead-based perovskites. $^{32,33}$ Therefore, tin-based perovskite films should be possible to be prepared by this technique. ${ }^{10,34}$ Here, the mixture 
Table 1 Crystallographic refinement details for the tin based perovskite polymorphs

\begin{tabular}{|c|c|c|c|c|c|c|c|}
\hline \multirow{3}{*}{$\frac{\text { Sample }}{\mathrm{B}-\gamma-\mathrm{CsSnI}_{3}}$} & \multirow{2}{*}{$\begin{array}{l}\text { Type } \\
\text { Cs-I }\end{array}$} & \multirow{2}{*}{$\begin{array}{l}\text { Bond length }(\AA) \\
4.09495\end{array}$} & \multicolumn{4}{|c|}{ Lattice constant $\left(\AA^{\mathrm{A}}\right.$ per $\left.^{\circ}\right)$} & \multirow{2}{*}{$\frac{\text { Ref. }}{38}$} \\
\hline & & & $a$ & 8.6885 & $\alpha=\beta=\gamma$ & 90 & \\
\hline & & & $b$ & 12.3775 & & & \\
\hline & Sn-I & 3.1685 & $c$ & 8.6384 & & & \\
\hline \multirow[t]{3}{*}{$\mathrm{Y}-\mathrm{CsSnI}_{3}$} & Cs-I & 4.0680 & $a$ & 10.350 & $\alpha=\beta=\gamma$ & 90 & 38 \\
\hline & Sn-I & 3.2475 & $b$ & 4.7632 & & & \\
\hline & & & $c$ & 17.684 & & & \\
\hline \multirow[t]{2}{*}{$\mathrm{Cs}_{2} \mathrm{SnI}_{6}$} & Cs-I & 4.2671 & $a=b=c$ & 11.6276 & $\alpha=\beta=\gamma$ & 90 & 6 \\
\hline & Sn-I & 2.9107 & & & & & \\
\hline \multirow[t]{2}{*}{$\mathrm{CsSnF}_{3}$} & Cs-F & 3.06629 & $a=b$ & 7.18763 & $\alpha=\beta$ & 90 & 43 \\
\hline & $\mathrm{Sn}-\mathrm{F}$ & 2.11543 & $c$ & 16.08594 & $\gamma$ & 120 & \\
\hline \multirow[t]{4}{*}{$\mathrm{CsSnI}_{3-x} \mathrm{~F}_{x}$ (non-optimized) } & Cs-I & 4.0215 & $a$ & 8.688 & $\alpha=\beta=\gamma$ & 90 & \\
\hline & Sn-I & 3.1143 & $b$ & 12.378 & & & \\
\hline & $\mathrm{Cs}-\mathrm{F}$ & 3.3794 & $c$ & 8.6430 & & & \\
\hline & $\mathrm{Sn}-\mathrm{F}$ & 3.2934 & & & & & \\
\hline
\end{tabular}

powder of $\mathrm{SnI}_{2}$ and CsI were evaporated onto the glass slide substrates by thermal vacuum evaporation method to form fully covered, dense, pinhole free $\mathrm{CsSnI}_{3}$ perovskite film. Also, by adding $\mathrm{SnF}_{2}$ powder into the mixture, the $\mathrm{CsSnI}_{3-x} \mathrm{~F}_{x}$ films were prepared as well. The evolution of the color, structure and properties of the annealed freshly and annealed aged $\mathrm{CsSnI}_{3-x} \mathrm{~F}_{x}$ films over time was observed, measured and analyzed to explore the effect of $\mathrm{F}$ doping.

\section{Experimental details}

\subsection{Sample preparation}

Cesium iodide ( $99.9 \%$ CsI), tin(II) fluoride $\left(99.99 \% \mathrm{SnF}_{2}\right.$ ) and tin iodide $\left(99.9 \% \mathrm{SnI}_{2}\right)$ were produced by Ying Kou You Xuan Trade Co., Ltd. China. Acetone (99.7\%) and ethanol (99.7\%) were purchased from Sinopharm Chemical Reagent Co., Ltd. China. Deionized water was filtered in the laboratory. All the reagents were of analytical grade and used as received.

The process of sample preparation was shown in Fig. S1. $\dagger$ Weighted $\mathrm{SnI}_{2}, \mathrm{SnF}_{2}$ and CsI powder was mixed in a mortar and placed in a tungsten boat of size $50 \times 15 \times 2 \mathrm{~mm}$, refer to Table 2. The AC power ( $50 \mathrm{~Hz}$ frequency) was applied to the tungsten boat through two connected electrodes, the glass slides, CAT. no. 7101 with a size of $25.4 \times 76.2 \mathrm{~mm}$, were ultrasonically cleaned in acetone for $900 \mathrm{~s}$, diluted by deionized water and ethanol before being loaded into the DM 450C vacuum chamber. The glass slide was held above the tungsten boat at a separation of $150 \mathrm{~mm}$. The chamber was pumped down to $2 \times$ $10^{-3} \mathrm{~Pa}$ and the $\mathrm{SnI}_{2}, \mathrm{SnF}_{2}$ and CsI was evaporated at a voltage of $70 \mathrm{~V}$ and current of $140 \mathrm{~A}$. The evaporation process referred to Tong..$^{35}$ The films were finally annealed at $210{ }^{\circ} \mathrm{C}$ for $4 \mathrm{~min}$ in argon gas by the Rapid Thermal Processor of RTP-500V.

\subsection{Measurement techniques}

The thicknesses of the films were measured by using a KLATencor Alpha-step D-100 type profilometer on a step created on the films by masking the glass substrates. The phases of the $\mathrm{CsSnI}_{3-x} \mathrm{~F}_{x}$ films were measured by X'Pert powder X-ray diffractometer (XRD) in glancing angle scanning mode at $0.5^{\circ}$ incident angle with $\mathrm{Cu} \mathrm{K} \alpha \mathrm{X}$-ray from $10^{\circ}$ to $80^{\circ}$, and analyzed by High-Score software. ${ }^{36}$ The electrical and optical properties of the $\mathrm{CsSnI}_{3-x} \mathrm{~F}_{x}$ films were measured by a HALL 8800 Hall Effect Measurement device and a CARY 5000 UV-Vis-NIR spectrometer over the wavelength range of 300 to $1000 \mathrm{~nm}$, respectively. AFM tests were performed in ambient conditions at room temperature with scanning probe microscopy (Bruker, Multimode 8 with controller V). A Pt/Ir-coated tip on a Si cantilever (tip radius of $20 \mathrm{~nm}$, force constant of $2.8 \mathrm{Nm}^{-1}$ and a resonant frequency of $75 \mathrm{kHz}$ ) was used to characterize the topography of the films. The typical tip-scanning velocity was $2 \mu \mathrm{m} \mathrm{s}^{-1}$.

\section{Results \& discussion}

\subsection{Morphological structure}

To demonstrate the macro-evolution process of the fluorine doped cesium tin iodine ( $\left.\mathrm{CsSnI}_{3-x} \mathrm{~F}_{x}\right)$ films, photographs of the colors of the freshly annealed and aged $\mathrm{CsSnI}_{3-x} \mathrm{~F}_{x}$ films exposed to ambient air were shown in Fig. 2a. With increasing

Table 2 The chemical composition of $\mathrm{CsSnl}_{3-x} \mathrm{~F}_{x}$ thin films

\begin{tabular}{lllll}
\hline Sample & CsI (mol) & SnI $_{2}(\mathrm{~mol})$ & $\mathrm{SnF}_{2}(\mathrm{~mol})$ & \multicolumn{1}{c}{ Proportion } \\
\hline $\mathrm{CSSnI}_{3}$ & 0.0025 & 0.0025 & 0 & $100: 100: 0$ \\
$\mathrm{CsSnI}_{2.88} \mathrm{~F}_{0.11}$ & 0.0025 & 0.0024 & 0.000094 & $100: 96.25: 3.75$ \\
$\mathrm{CsSnI}_{2.78} \mathrm{~F}_{0.22}$ & 0.0025 & 0.0023 & 0.000190 & $100: 92.5: 7.5$ \\
$\mathrm{CsSnI}_{2.67} \mathrm{~F}_{0.33}$ & 0.0025 & 0.0022 & 0.000280 & $100: 88.75: 11.25$
\end{tabular}


(a)

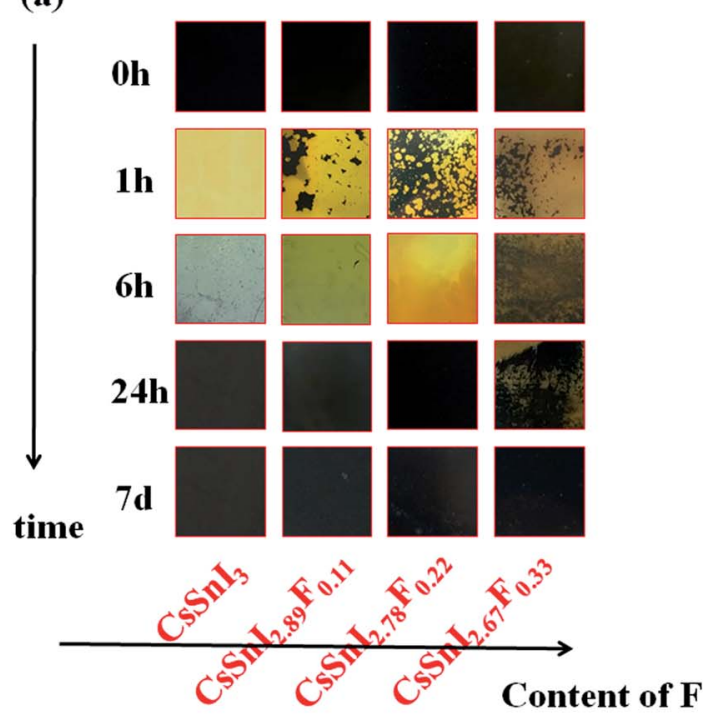

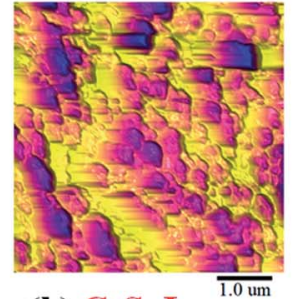

(b) $\mathrm{CsSnI}_{3}$

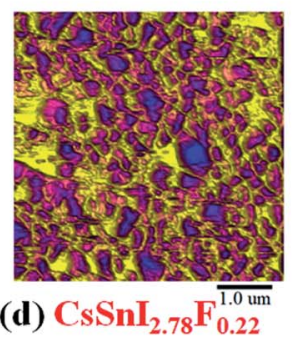

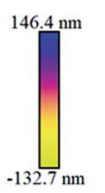
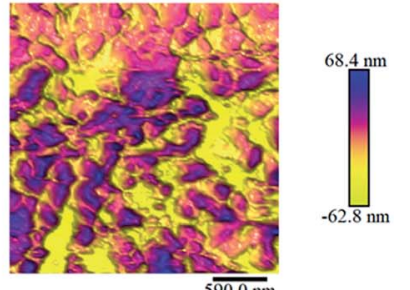

(c) $\mathrm{CsSnI}_{2.89} \mathrm{~F}_{0.11}$
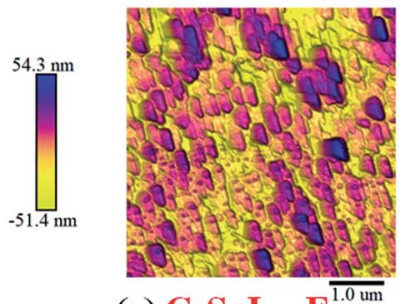

(e) $\mathrm{CsSnI}_{2.67} \mathrm{~F}_{0.33}^{1.0 \mathrm{um}}$

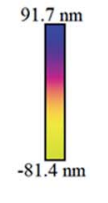

Fig. 2 (a) Macroscopic images of the evolution in the cesium tin iodine doped fluorine ( $\left.\mathrm{CsSnl}_{3-x} \mathrm{~F}_{x}\right)$ films. (b-e) AFM images of the cesium tin iodine doped fluorine $\left(\mathrm{CsSnl}_{3-x} \mathrm{~F}_{x}\right)$ with different fluorine content, (b-e) correspond to $\mathrm{CsSnl}_{3}, \mathrm{CsSnl}_{2.89} \mathrm{~F}_{0.11}, \mathrm{CsSnl}_{2.78} \mathrm{~F}_{0.22}, \mathrm{CsSnl}_{2.67} \mathrm{~F}_{0.33}$, respectively.

time, the colors of the films changed from black to yellow, and finally presented as black again. These colors served as a good indication of the oxidation progress of $\mathrm{B}-\gamma / \mathrm{Y}-\mathrm{CsSnI}_{3}$ to $\mathrm{Cs}_{2} \mathrm{SnI}_{6}$ in air. ${ }^{37}$ It is evident from a comparison of the photographs in Fig. 2a that doping $\mathrm{F}$ slowed down the transformation process of the perovskite phases, since the color of $\mathrm{F}$ doped films were predominantly yellow after six hours exposure in air, whereas that of the $\mathrm{CsSnI}_{3}$ film without fluorine dopant had almost completely blackened. The morphologies of the corresponding $\mathrm{CsSnI}_{3-x} \mathrm{~F}_{x}$ films were examined by AFM, respectively (see Fig. 2b-e). Strikingly, no pinhole appeared in entire scope in the $\mathrm{CsSnI}_{3-x} \mathrm{~F}_{x}$ films. Furthermore, the grain sizes became finer as the amount of doped fluorine increased.

\subsection{Phase structure}

Corroborating evidence for the process of phase transition in $\mathrm{CsSnI}_{3-x} \mathrm{~F}_{x}$ films lexposed in air was provided by X-ray diffraction (XRD), shown in Fig. 3a and b, which were consistent with the variations in morphology. Firstly, for the annealed $\mathrm{CsSnI}_{3-x} \mathrm{~F}_{x}$ films (see Fig. 3a), the peaks at $25.11^{\circ}$, $29.08^{\circ}$ and $41.45^{\circ}$ were attributed to $\mathrm{B}-\gamma-\mathrm{CsSnI}_{3}$ phase (022), (220) and (224) planes (Ref.Code: 01-043-1162), respectively. Meanwhile, the well-matched peaks of $27.61^{\circ}$ and $39.44^{\circ}$, assigned to CsI phase (110) and (200) planes (Ref.Code: 01-0772185), were observed. However, the annealed XRD patterns also showed Y-CsSnI 3 phase (111) and (121) planes (Ref.Code: 01-071-1898). The B- $\gamma-\mathrm{CsSnI}_{3}$ peaks of the annealed $\mathrm{CsSnI}_{3-x} \mathrm{~F}_{x}$ films became more distinct with the increase of $\mathrm{F}$ dopant ratios whilst the $\mathrm{Y}-\mathrm{CsSnI}_{3}$ peaks became weaker. Although stoichiometric ratios were strictly controlled, the sharp and high intensity peaks of CsI also appeared in the XRD patterns, this can be attributed to incomplete reaction with $\mathrm{SnI}_{2}$, because $\mathrm{SnI}_{2}$ (vaporization point $993.15 \mathrm{~K}$ in ambient air) is easier to evaporate and decompose (unstable $\mathrm{Sn}^{2+}$ ) than CsI
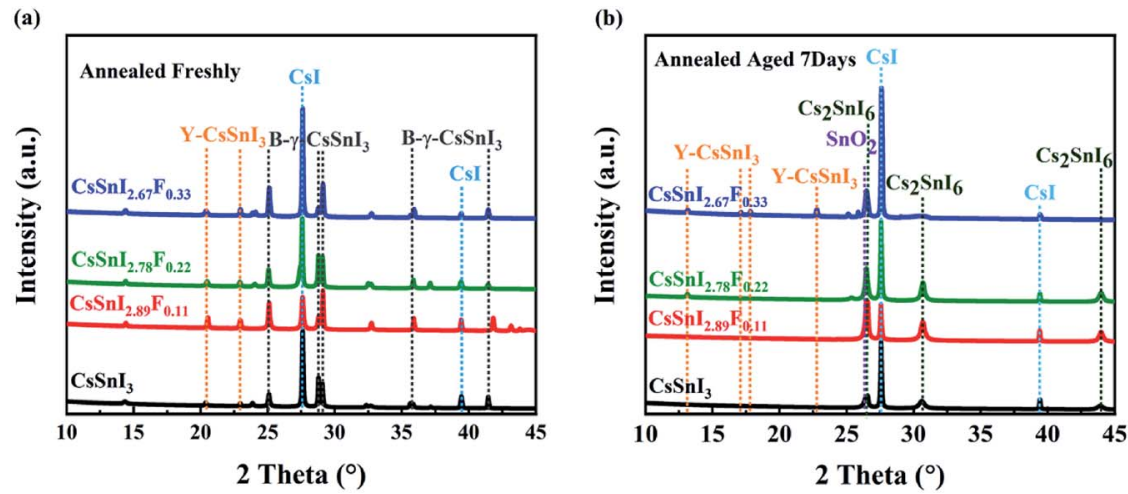

Fig. 3 Evolution of XRD patterns of $\mathrm{CsSnl}_{3-x} \mathrm{~F}_{x}$ films with time. (a) XRD patterns of the $\mathrm{CsSnl}_{3_{-} \mathrm{F}_{x}}$ films annealed freshly, (b) XRD patterns of the annealed $\mathrm{CsSnl}_{3-x} \mathrm{~F}_{x}$ films exposed in air for 7 days. 
(vaporization point $1553 \mathrm{~K}$ in ambient air) in the process of thermal evaporation. The variations of the XRD patterns show that fluorine doping obstructed the transformation from B- $\gamma$ $\mathrm{CsSnI}_{3}$ to $\mathrm{Y}-\mathrm{CsSnI}_{3}$ perovskite phases.

After aging seven days in air, the films returned to a light black color. This phenomenon is consistent with the trend of Qiu's experiment. ${ }^{37}$ The new diffraction peaks (see Fig. $3 \mathrm{~b})$ at $26.44^{\circ}, 30.61^{\circ}$, and $43.91^{\circ}$ were attributed to the (222), (004) and (044) orientations of $\mathrm{Cs}_{2} \mathrm{SnI}_{6}$ phase (Ref.Code: 00-051-0466). However, the aged XRD patterns showed (120), (121), (130) and (210) planes of the Y-CsSnI phase. Furthermore, several diffraction peaks at $27.57^{\circ}$, $39.41^{\circ}$, and $26.58^{\circ}$ assigned to CsI and $\mathrm{SnO}_{2}$ (Ref.Code: 00077-0448) were observed as well. Again, the Y-CsSnI ${ }_{3}$ phase was much obvious with the increase of $\mathrm{F}$ dopant ratios, which meant $\mathrm{F}$ doping delayed the phase transformation, and $\mathrm{Y}$ phase existed in the highly $\mathrm{F}$ doped films even after aging for seven days.

Based on these findings via the above XRD data, partial CsI, $\mathrm{SnI}_{2}$, and $\mathrm{SnO}_{2}$ peaks were observed during the evolution process of the $\mathrm{CsSnI}_{3-x} \mathrm{~F}_{x}$ films, the chemical reactions involved may be as follows:

$$
\mathrm{CsSnI}_{3-x} \mathrm{~F}_{x} \stackrel{\mathrm{T}, \mathrm{H}_{2} \mathrm{O}, \mathrm{O}_{2}, \text { et al. }}{\longrightarrow} \mathrm{Cs}_{2} \mathrm{SnI}_{6-x}\left(\mathrm{~F}_{x}\right)+\mathrm{SnO}_{2}
$$

Therefore, it is clear that this process was due to oxidation of $\mathrm{Sn}$ in the compounds. ${ }^{6} \mathrm{Sn}^{2+}$ ions are quite sensitive to external oxygen, especially in humid environments, which can be oxidized to more stable $\mathrm{Sn}^{4+}$ analogues. This oxidation process may fundamentally destroy the charge neutrality of the $\mathrm{CsSnI}_{3}$ perovskite structure and lead to phase transition. The Sn-F bonds form when fluorine replaces iodide in the lattice. The Sn-F bond length is shorter than that of $\mathrm{Sn}-\mathrm{I}$, resulting in a more stable crystal structure and weakening the role of oxygen, refer to Fig. S2. $\dagger$ In short, doping with fluorine slowed down the oxidation progress of the $\mathrm{Sn}^{2+}$ in $\mathrm{CsSnI}_{3}$ into $\mathrm{Sn}^{4+}$. The B- $\gamma-\mathrm{CsSnI}_{3-x}(\mathrm{~F})_{x}$ phase eventually transferred into $\mathrm{Cs}_{2} \mathrm{SnI}_{6-x}(\mathrm{~F})_{x}$ and was accompanied by the formation of $\mathrm{SnO}_{2}$ over time, but the formation processes are delayed by the additional $\mathrm{F}$ dopant. The remnant $\mathrm{Y}$ $\mathrm{CsSnI}_{3}$ phase proved not only to delay the phase transition, but also the existence of $\mathrm{Sn}^{2+}$. The hybrid of $\mathrm{Sn}^{4+}$ with $\mathrm{Sn}^{2+}$ resulted in the $\mathrm{Cs}_{2} \mathrm{SnI}_{6-x}(\mathrm{~F})_{x}$ films showing their p type property.

\subsection{Electrical properties of $\mathrm{CsSnI}_{3-x} \mathrm{~F}_{x}$ films}

The electrical properties and thickness of the $\mathrm{CsSnI}_{3-x} \mathrm{~F}_{x}$ films at room temperature were measured by a HALL 8800
Hall Effect Measurement device and KLA-Tencor Alpha-step D-100 type profilometer respectively. The results were shown in Table 3 for the freshly annealed and Table 4 for those aged seven days after annealing. In this case, the thicknesses of the films were used to calculate the resistivity of the films. Both the annealed and aged $\mathrm{CsSnI}_{3-x} \mathrm{~F}_{x}$ films were $\mathrm{p}$ type semiconductors with the holes provided by the Sn vacancies. Intrinsic defects such as Sn vacancies in the ternary Cs-Sn-I system gave rise to p-type conductivity ${ }^{20}$ and DFT calculations have shown that the formation energy of $\mathrm{V}_{\text {Sn }}$ defects was the lowest among all defects. ${ }^{38}$ In Table 3, the freshly annealed $\mathrm{CsSnI}_{3}$ film exhibited the carrier densities of $\sim 10^{14} \mathrm{~cm}^{-3}$, and the carrier density of $\mathrm{CsSnI}_{3-x} \mathrm{~F}_{x}$ films increased to $\sim 10^{16} \mathrm{~cm}^{-3}$ with the increase of $\mathrm{SnF}_{2}$ content. It's also worth noting that the resistivities of $\mathrm{CsSnI}_{3-x} \mathrm{~F}_{x}$ films were 1-2 orders of magnitude smaller than that of undoped film. The reduction of the Sn vacancy concentrations can be attributed to the strong bonding energy between $\mathrm{F}$ and $\mathrm{Sn}$.

After aging in air for seven days, the electrical properties of the $\mathrm{CsSnI}_{3-x} \mathrm{~F}_{x}$ films kept the same order. As described in Section 3.2 Phase structure, the main composition of the $\mathrm{CsSnI}_{3-x} \mathrm{~F}_{x}$ films was $\mathrm{Cs}_{2} \mathrm{SnI}_{6}$. This is accompanied by the generation of a mass of $\mathrm{Sn}$ vacancies. The carrier densities of the aged $\mathrm{CsSnI}_{3-x} \mathrm{~F}_{x}$ films were almost at the same level in comparison to those of the annealed $\mathrm{CsSnI}_{3-x} \mathrm{~F}_{x}$ films. The resistivities of $\mathrm{CsSnI}_{3-x} \mathrm{~F}_{x}$ films were still relatively small. After aging for seven days, the phase transformation occurred, the oxidation of tin was completed, and the double layer 'vacancy ordered' phase $\mathrm{Cs}_{2} \mathrm{SnI}_{6-x} \mathrm{~F}_{x}$ formed. As the results, the Sn vacancies of the aged films were high, and their carrier density increased sharply. However, the rate of increase of the charge carriers of the aged films decreased with the increase of $\mathrm{SnF}_{2}$ content. The phases were stable due to F doping, the creation processes of the Sn vacancies were delayed and therefore, the changes of the electrical properties were slower. This fully illustrates $\mathrm{SnF}_{2}$ hindering the oxidation process of $\mathrm{Sn}^{2+}$, which blocked the formation of $\mathrm{Cs}_{2} \mathrm{SnI}_{6}$.

Since the carrier (hole or electron) concentration of semiconductor depends on the inherent defect concentration, the control of carrier concentration is a necessary condition to optimize the performance of solar cells. It works better as the hole-transport material (HTM) when hole concentration and conductivity are high, but it may work better as the light absorber material (LAM) when hole concentration and conductivity are moderate. ${ }^{39}$ From the data of electrical properties, by tuning the F doping amount, hole concentration and

Table 3 The electrical properties and thickness of $\mathrm{CsSnl}_{3-x} \mathrm{~F}_{x}$ thin films annealed freshly

\begin{tabular}{|c|c|c|c|c|c|c|}
\hline Sample & $R_{\mathrm{S}}\left(\Omega \square^{-1}\right)$ & $\rho(\Omega \mathrm{cm})$ & $\mathrm{N} / \mathrm{P}\left(\mathrm{cm}^{-3}\right)$ & $\mu\left(\mathrm{cm}^{2} \mathrm{~V}^{-1} \mathrm{~s}^{-1}\right)$ & Thickness (nm) & Type \\
\hline $\mathrm{CsSnI}_{3}$ & $2.14 \times 10^{5}$ & 22.71 & $6.12 \times 10^{14}$ & 449.31 & 1060 & $\mathrm{P}$ \\
\hline $\mathrm{CsSnI}_{2.88} \mathrm{~F}_{0.11}$ & $1.93 \times 10^{4}$ & 4.65 & $5.84 \times 10^{15}$ & 229.55 & 2410 & $\mathrm{P}$ \\
\hline $\mathrm{CsSnI}_{2.67} \mathrm{~F}_{0.33}$ & $1.49 \times 10^{3}$ & 0.394 & $7.29 \times 10^{16}$ & 217.34 & 2650 & $P$ \\
\hline
\end{tabular}


Table 4 The electrical properties and thickness of $\mathrm{CsSn}_{3-x} \mathrm{~F}_{x}$ thin films annealed aged 7 days in air

\begin{tabular}{|c|c|c|c|c|c|c|}
\hline Sample & $R_{\mathrm{S}}\left(\Omega \square^{-1}\right)$ & $\rho(\Omega \mathrm{cm})$ & $\mathrm{N} / \mathrm{P}\left(\mathrm{cm}^{-3}\right)$ & $\mu\left(\mathrm{cm}^{2} \mathrm{~V}^{-1} \mathrm{~s}^{-1}\right)$ & Thickness (nm) & Type \\
\hline $\mathrm{CsSnI}_{3}$ & $3.62 \times 10^{5}$ & 38.75 & $1.42 \times 10^{15}$ & 114.96 & 1060 & $\mathrm{P}$ \\
\hline $\mathrm{CsSnI}_{2.88} \mathrm{~F}_{0.11}$ & $4.07 \times 10^{4}$ & 9.79 & $8.55 \times 10^{15}$ & 74.55 & 2410 & $\mathrm{P}$ \\
\hline $\mathrm{CsSnI}_{2.67} \mathrm{~F}_{0.33}$ & $3.54 \times 10^{5}$ & 93.75 & $1.45 \times 10^{16}$ & 4.59 & 2650 & $\mathrm{P}$ \\
\hline
\end{tabular}

conductivity can be controlled, so that the film can be selectively arranged as HTM and LAM.

\subsection{Optical properties}

The absorptive spectra of the annealed and aged $\mathrm{CsSnI}_{3-x} \mathrm{~F}_{x}$ films within the range of $400-1400 \mathrm{~nm}$ were presented in Fig. $4 \mathrm{a}$ and c, respectively. Within the UV range, the absorptivity of the films was almost the same. The absorption edges of the annealed and aged $\mathrm{CsSnI}_{3-x} \mathrm{~F}_{x}$ films exhibited obvious differences. With the addition of $\mathrm{SnF}_{2}$, the light harvesting in the visible light region of the solar spectrum of the $\mathrm{CsSnI}_{3-x} \mathrm{~F}_{x}$ films was significantly enhanced. These differences indicate the difference of the band gap between samples. The spectra of the absorption via optical band gaps of the annealed and aged films were shown in Fig. $4 \mathrm{~b}$ and $\mathrm{d}$, which were calculated by the formula of $\alpha h \theta=A\left(h \theta-E_{\mathrm{g}}\right)^{1 / 2}$. The Tauc plot $^{40}$ is used to evaluate the optical energy gap. The bandgaps of all the $\mathrm{CsSnI}_{3-x} \mathrm{~F}_{x}$ films are between $1.25 \mathrm{eV}$ and $1.3 \mathrm{eV}$ as shown in Fig. $4 \mathrm{~b}$ which was consistent with those previously reported. ${ }^{41}$

The optical spectra of $\mathrm{CsSnI}_{3-x} \mathrm{~F}_{x}$ films under exposure to ambient air for seven days are shown in Fig. $4 \mathrm{c}$ and d. The absorption edges of all the $\mathrm{CsSnI}_{3-x} \mathrm{~F}_{x}$ films exhibited blue shift. All the bandgaps for the $\mathrm{F}$ doped films got smaller, and was close to $1.48 \mathrm{eV}$ derived in Qiu's report. ${ }^{37}$ This is a result of $\mathrm{SnF}_{2}$ eliminating the formation of weak unidentified reflections due to the $\mathrm{Y}_{-} \mathrm{CsSnI}_{3}$ phase. ${ }^{42}$ After the $\mathrm{CsSnI}_{3-x} \mathrm{~F}_{x}$ films under exposure to ambient air for seven days, the $\mathrm{Y}-\mathrm{CsSnI}_{3}$ phase only was shown in the highly $\mathrm{F}$ doped films, which the fully (a)

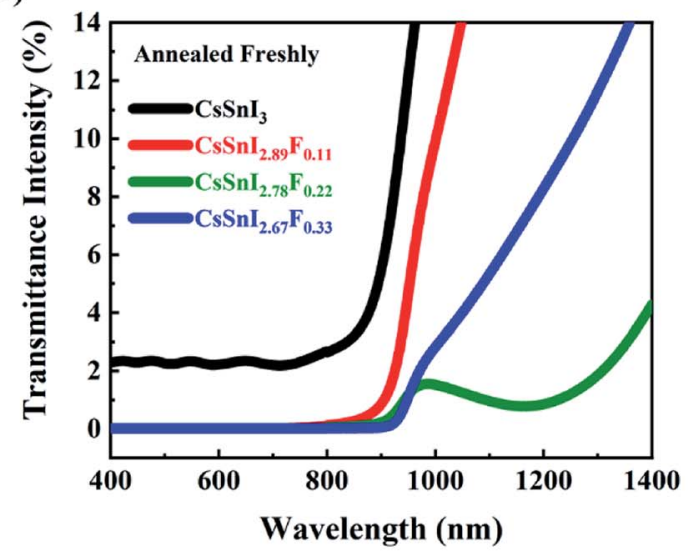

(c)

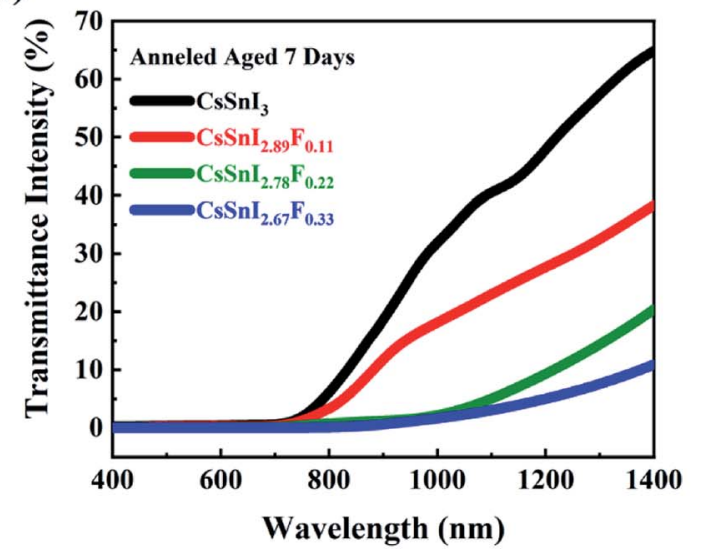

(b)

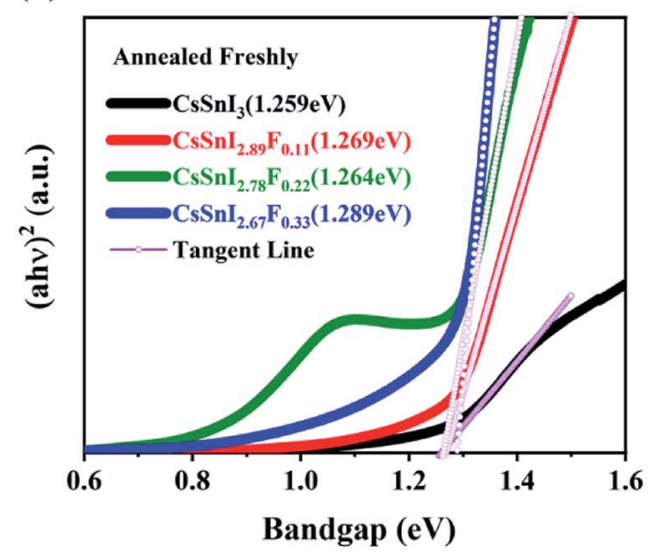

(d)

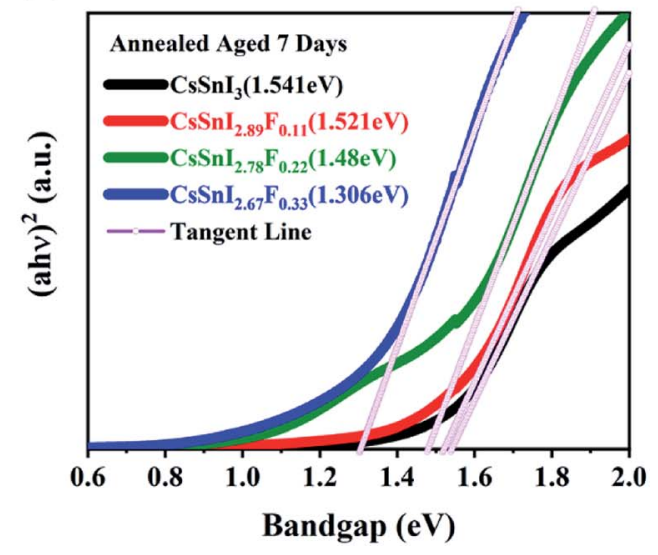

Fig. 4 Optical spectra of $\mathrm{CsSnl}_{3-x} \mathrm{~F}_{x}$ films:( $\mathrm{a}$ and b) annealed freshly; (c and d) under exposure to ambient air for 7 days. 
illustrates the role of $\mathrm{SnF}_{2}$. The transmittance of the $\mathrm{Cs}_{2} \mathrm{SnI}(\mathrm{F})_{6}$ films within visible wavelength were strongly affected by doping $\mathrm{F}$ ions due to the decomposition of $\mathrm{CsSnI}_{3-x} \mathrm{~F}_{x}$. It was further shown that $\mathrm{SnF}_{2}$ blocked the formation of $\mathrm{Cs}_{2} \mathrm{SnI}_{6}$ by the changes of bandgap. Note that the sunlight absorption in the red and near-infrared regions has been a challenge for solar cells, and the excellent optical properties of $\mathrm{CsSnI}_{3-x} \mathrm{~F}_{x}$ films made up for this defect.

\section{Conclusion}

$\mathrm{CsSnI}_{3}$ transformed into stable double layer perovskite $\mathrm{Cs}_{2} \mathrm{SnI}_{6}$ phase in air was investigated for potential solar cell applications. By conducting a series of experiments, it was determined that the phase transformation in air can be slowed down by doping $\mathrm{F}$ ions into $\mathrm{CsSnI}_{3}$. The mechanism of phase transition delay is that $\mathrm{Sn}^{2+}$ preferentially bonds with $\mathrm{F}^{-}$, and thus the process of $\mathrm{Sn}^{2+}$ in $\mathrm{CsSnI}_{3}$ to be oxidized into $\mathrm{Sn}^{4+}$ was slowed down. The B- $\gamma-\operatorname{CsSnI}(\mathrm{F})_{3}$ phase eventually formed $\mathrm{Cs}_{2} \mathrm{SnI}(\mathrm{F})_{6}$ accompanied by the formation of the $\mathrm{SnO}_{2}$ phase over time, but the transition processes are delayed by the additional $\mathrm{F}$ dopant.

Furthermore, $\mathrm{SnF}_{2}$ improved the carrier concentration and conductivity of the film, in which the resistivities of $\mathrm{CsSnI}_{3-x} \mathrm{~F}_{x}$ films were less than $10 \Omega \mathrm{cm}$ except $\operatorname{CsSnI}_{2.67} \mathrm{~F}_{0.33}$. The $\mathrm{CsSnI}_{3-x} \mathrm{~F}_{x}$ films also absorbed more visible and infrared light with increased $\mathrm{F}$ doping than the pure $\mathrm{CsSnI}_{3}$ film. It was further shown that $\mathrm{SnF}_{2}$ blocked the formation of $\mathrm{Cs}_{2} \mathrm{SnI}_{6}$ by comparing the changes of bandgaps. The usage of $\mathrm{CsSnI}_{3-x} \mathrm{~F}_{x}$ films as HTM or LAM in solar cells is envisioned to be a promising method of improving efficiency.

\section{Conflicts of interest}

There are no conflicts to declare.

\section{Acknowledgements}

The work at University of Science and Technology Liaoning is supported by National Natural Science Foundation of China (No. 51672119, 51774180, 51972155) and Royal Society International Exchanges 2017(IEC \NSFC $\backslash 170535)$. Acknowledges go to the support from the Project of Young Teachers in the Higher Education Institutions of USTL (No. 2017QN13) and the Innovation Team Project of USTL (No. 2017TD01). Thanks go to the colleagues at Manchester Metropolitan University for their cooperation in this study.

\section{References}

1 A. Kojima, K. Teshima, Y. Shirai and T. Miyasaka, J. Am. Chem. Soc., 2009, 131, 6050-6051.

2 Q. Jiang, Y. Zhao, X. Zhang, X. Yang, Y. Chen, Z. Chu, Q. Ye, X. Li, Z. Yin and J. You, Nat. Photonics, 2019, 13, 460-466.

3 J. H. Im, H. S. Kim and N. G. Park, APL Mater., 2014, 2, 591713.

4 I. Chung, B. Lee, J. He, R. P. Chang and M. G. Kanatzidis, Nature, 2012, 485, 486-489.
5 N. R. E. Laboratory, Best Research-Cell Efficiencies chart, http://www.nrel.gov/ncpv/images/efficiency_chart.jpg.

6 C. C. Stoumpos, C. D. Malliakas and M. G. Kanatzidis, Inorg. Chem., 2013, 52, 9019-9038.

7 P. P. Boix, S. Agarwala, T. M. Koh, N. Mathews and S. G. Mhaisalkar, J. Phys. Chem. Lett., 2015, 6, 898-907.

8 P. Pyykko, Chem. Rev., 1988, 88, 563-594.

9 N. K. Noel, S. D. Stranks, A. Abate, C. Wehrenfennig, S. Guarnera, A. A. Haghighirad, A. Sadhanala, G. E. Eperon, S. K. Pathak and M. B. Johnston, Energy Environ. Sci., 2014, 7, 3061-3068.

10 D. Moghe, L. Wang, C. J. Traverse, A. Redoute, M. Sponseller, P. R. Brown, V. Bulović and R. R. Lunt, Nano Energy, 2016, 28, 469-474.

11 L. Glasser, Inorg. Chem., 2012, 51, 2420.

12 K. Yamada, S. Funabiki, H. Horimoto, T. Matsui, T. Okuda and S. Ichiba, Chem. Lett., 1991, 20, 801-804.

13 P. Mauersberger and F. Huber, Acta Crystallogr., Sect. B: Struct. Crystallogr. Cryst. Chem., 1980, 36, 683-684.

14 A. E. Maughan, A. M. Ganose, M. M. Bordelon, E. M. Miller, D. O. Scanlon and J. R. Neilson, J. Am. Chem. Soc., 2016, 138, 8453-8464.

15 S. Vilminot, W. Granier, A. Soufiane, L. Cot, J. M. Letoffe and P. Claudy, Rev. Chim. Miner., 1985, 22, 125-133.

16 T. Thao Tran and P. Shiv Halasyamani, J. Solid State Chem., 2014, 210, 213-218.

17 W. B. Schaap, J. A. Davis and W. H. Nebergall, J. Am. Chem. Soc., 1954, 76, 5226-5229.

18 C. A. Randall, A. S. Bhalla, T. R. Shrout and L. E. Cross, J. Mater. Res., 1990, 5, 829-834.

19 T. M. Koh, T. Krishnamoorthy, N. Yantara, C. Shi, W. L. Leong, P. P. Boix, A. C. Grimsdale, S. G. Mhaisalkar and N. Mathews, J. Mater. Chem. A, 2015, 3, 14996-15000.

20 M. H. Kumar, S. Dharani, W. L. Leong, P. P. Boix, R. R. Prabhakar, T. Baikie, C. Shi, H. Ding, R. Ramesh and M. Asta, Adv. Mater., 2014, 26, 7122-7127.

21 F. Hao, C. C. Stoumpos, P. Guo, N. Zhou, T. J. Marks, R. P. H. Chang and M. G. Kanatzidis, J. Am. Chem. Soc., 2015, 137, 11445-11452.

22 S. J. Lee, S. S. Shin, Y. C. Kim, D. Kim, T. K. Ahn, J. H. Noh, J. Seo and S. I. Seok, J. Am. Chem. Soc., 2016, 138, 3974-3977.

23 A. Dualeh, N. Tétreault, T. Moehl, P. Gao, M. K. Nazeeruddin and M. Grätzel, Adv. Funct. Mater., 2014, 24, 3250-3258.

24 G. E. Eperon, V. M. Burlakov, P. Docampo, A. Goriely and H. J. Snaith, Adv. Funct. Mater., 2014, 24, 151-157.

25 T. Leijtens, B. Lauber, G. E. Eperon, S. D. Stranks and H. J. Snaith, J. Phys. Chem. Lett., 2014, 5, 1096-1102.

26 W. Qi, Y. Shao, Q. Dong, Z. Xiao, Y. Yuan and J. Huang, Energy Environ. Sci., 2014, 7, 2359-2365.

27 L. Po-Wei, L. Chien-Yi, C. Chu-Chen, Z. Fan, S. T. Williams, X. Xu-Kai, L. Jiangjen and J. K.-Y. Alex, Adv. Mater., 2014, 26, 3748-3754.

28 Y. Zhao and K. Zhu, J. Phys. Chem. C, 2014, 118.

29 D. Shen, X. Yu, X. Cai, M. Peng, Y. Ma, X. Su, L. Xiao and D. Zou, J. Mater. Chem. A, 2014, 2, 20454-20461.

30 S. Paek, N. Cho, H. Choi, H. Jeong, S. L. Jin, J. Y. Hwang, J. K. Lee and J. Ko, J. Phys. Chem. C, 2014, 118, 25899-25905. 
31 K. Hak-Beom, C. Hyosung, J. Jaeki, K. Seongbeom, W. Bright, S. Seyeong and K. J. Young, Nanoscale, 2014, 6, 6679-6683.

32 M. Liu, M. B. Johnston and H. J. Snaith, Nature, 2013, 501, 395.

33 Q. Chen, H. Zhou, Z. Hong, S. Luo, H. S. Duan, H. H. Wang, Y. Liu, G. Li and Y. Yang, J. Am. Chem. Soc., 2014, 136, 622625.

34 B. Wu, Y. Zhou, G. Xing, Q. Xu, H. F. Garces, A. Solanki, T. W. Goh, N. P. Padture and T. C. Sum, Adv. Funct. Mater., 2017, 27, 1604818.

35 X. R. Tong, Z. Zhao, J. S. Wu, Y. W. Zhou, P. Kelly and P. Gao, Nanosci. Nanotechnol. Lett., 2018, 10, 329-336.

36 T. Degen, M. Sadki, E. Bron, U. Konig and G. Nenert, Powder Diffr., 2014, 29, S13-S18.
37 X. Qiu, B. Cao, Y. Shuai, X. Chen, Z. Qiu, Y. Jiang, Y. Qian, H. Wang, H. Zeng and L. Jian, Sol. Energy Mater. Sol. Cells, 2017, 159, 227-234.

38 I. Chung, J.-H. Song, J. Im, J. Androulakis, C. D. Malliakas, H. Li, A. J. Freeman, J. T. Kenney and M. G. Kanatzidis, J. Am. Chem. Soc., 2012, 134, 8579-8587.

39 Z. Xiao, Y. Zhou, H. Hosono and T. Kamiya, Phys. Chem. Chem. Phys., 2015, 17, 18900-18903.

40 J. D. Neufville and H. Rockstad, 1974.

41 L. Byunghong, C. C. Stoumpos, Z. Nanjia, H. Feng, M. Christos, Y. Chen-Yu, T. J. Marks, M. G. Kanatzidis and R. P. H. Chang, J. Am. Chem. Soc., 2014, 136, 15379-15385.

42 Y. Zhou, H. F. Garces, B. S. Senturk, A. L. Ortiz and N. P. Padture, Mater. Lett., 2013, 110, 127-129.

43 S. Körbel, M. A. L. Marques and S. Botti, J. Mater. Chem. C, 2016, 4, 3157-3167. 